\title{
ESTADO SOCIAL E
}

\section{DEMOCRÁTICO DE DIREITO E}

\section{EFETIVIDADE CONSTITUCIONAL:} CONSIDERAÇÕES SOBRE O PAPEL DAS POLÍTICAS PÚBLICAS EM

, FACE DA CONCRETIZAÇÃO DE DIREITOS FUNDAMENTAIS

\author{
BETINA DA SILVA ADAMI
}




\title{
ESTADO SOCIAL E DEMOCRÁTICO DE DIREITO E EFETIVIDADE CONSTITUCIONAL: CONSIDERAÇÕES SOBRE O PAPEL DAS POLÍTICAS PÚBLICAS EM FACE DA CONCRETIZAÇÃO DE DIREITOS FUNDAMENTAIS
}

Betina da Silva Adami ${ }^{1}$

RESUMO

O presente artigo tem por finalidade analisar as imbricações entre o Estado Social e Democrático de Direito contemporâneo e o conceito de políticas públicas, como forma de intervir na planificação das ações estatais e, assim, outorgar maior efetividade aos direitos fundamentais. Em um primeiro momento, portanto, aborda-se a perspectiva que permeia a noção de Estado Social e Democrático de Direito bem como se percorre brevemente sobre pontos centrais do seu desenvolvimento histórico. Posteriormente, trata-se do conceito de políticas públicas e da sua fundamental importância para a efetividade dos direitos fundamentais consagrados na Constituição Federal de 1988.

\section{Palavras-chave:}

Estado Social e Democrático de Direito - Direitos Fundamentais Efetividade-Políticas Públicas

\begin{abstract}
This article aims to analyze the relations between the contemporary Democratic and Social State of Law and the concept of public policies as a way to intervene in the planning of governmental actions and, thereby, confer greater effectiveness to fundamental rights. At first, therefore, deals with the perspective that permeates the notion of Social and Democratic State of Law as well as outlines briefly the central points of its historical development. Subsequently, the analysis focuses the concept of public policy and its fundamental importance for the realization of fundamental rights enshrined in the Constitution of 1988.
\end{abstract}

Key-words:

Democratic and Social State of Law - Fundamental Rights - Effectiveness -

'Advogada no Rio Grande do Sul, Mestre em Direito Público pela Pontificia Universidade Católica do Rio Grande do Sul (PUCRS) e integrante do Núcleo de Estudos em Direitos Fundamentais, vinculado ao CNPQ. e-mail: betina.adami@gmail.com 
Public Policy

\section{INTRODUÇÃO}

As transformações por que passa o Estado implicam analisar também as conseqüências projetadas para a produção, interpretação e aplicação do Direito. Acompanhando as diferentes formas de Estado, também se podem observar significativas diferenças na forma de conceber o Direito.

Ao Estado e ao Direito, na contemporaneidade, são colocados novos desafios, que demandam a reflexão sobre as formas como eles interferem na dinâmica social. Tal assertiva é posta tendo em vista tanto as atribuições constitucionais que marcam a conformação jurídico-constitucional a partir do Segundo Pós-Guerra Mundial, como em decorrência de novos padrões sociais, econômicos e culturais que agem sobre a estruturação tradicional do Estado (soberania, território e povo).

Nesse contexto, o presente artigo tem como objetivo analisar, mesmo que não se possa fazê-lo de forma exaustiva, as repercussões e imbricações que o conceito de políticas públicas tem (a partir e) sobre o Estado Social e Democrático de Direito projetado a partir da Constituição Federal de 1988.

\section{A CONFIGURAÇÃO DO ESTADO A PARTIR DAS CONSTITUIÇÕES CONTEMPORÂNEAS (O ESTADO SOCIAL E DEMOCRÁTICO DE DIREITO)}

Primeiramente, com o objetivo de situar, tanto no plano da Teoria do Estado como no contexto jurídico-constitucional a questão ora proposta, faz-se importante esclarecer a perspectiva que envolve a presente análise. Assim, refere-se que se toma como marco teórico da presente investigação o Estado Democrático de Direito contemporâneo, bem como se buscará percorrer, mesmo que de forma breve, os aspectos que marcam a evolução desse Estado.

O Estado Democrático de Direito, formação do Estado constitucional, assenta-se numa perspectiva global de transformação da realidade, não se restringindo, como cabia ao Estado Social, a "uma adaptação melhorada das condições sociais 
de existência ${ }^{2} . "$

Os novos parâmetros substantivos que permeiam a conformação do Estado Democrático de Direito contemporâneo reintroduzem a consideração dos fins e valores que a sociedade e o Estado devem promover. Daí por que Diogo de Figueiredo Moreira Neto afirmar que os parâmetros substantivos - os princípios da realidade, razoabilidade e interdição do arbítrio - do Estado de Direito, que tiveram o seu "reconhecimento indispensáveis ao funcionamento dos sistemas de garantias dos direitos fundamentais", sozinhos não contemplam mais as necessidades complexas do Estado contemporâneo ${ }^{3}$.

Importa fazer referência à característica que irá conformar a diferenciação entre o Estado de Direito e o Estado Democrático e de Direito. Nesse sentido, na esteira das proposições de Perez-Luño, ${ }^{4}$ salienta-se a oposição entre a noção de liberdade como autonomia de inspiração democrática e um conceito de liberdade como não ingerência na esfera privada, de inequívoco sentido liberal.

$\mathrm{Se}$, tradicionalmente, o Liberalismo é identificado como um impedimento do Estado para interferir nos assuntos privados, integrando-se aqui também a liberdade de comércio, o Estado Liberal de Direito promoverá a demarcação jurídica das fronteiras dessa não-intervenção. $\mathrm{O}$ alcance do Estado Liberal deve atingir tão somente a garantia da manutenção de disposição das liberdades fundamentais, incumbindo-lhe a conservação da ordem pública por um aparelhamento policial de poder. Em razão disso, como apontam Lenio Streck e José Luiz Bolzan de Morais, "é que o Direito, próprio a este Estado, terá como característica central e como metodologia eficacial a coerção das atitudes, tendo como mecanismo fundamental a sanção.",

\footnotetext{
${ }^{2}$ STRECK, Lenio Luiz; MORAIS, José Luis Bolzan de. Ciência Politica e Teoria Geral do Estado. 3 ed. Porto Alegre: Livraria do Advogado, 2003, p. 93.

${ }^{3}$ NETO, Diogo de Figueiredo Moreira. Juridicidade, pluralidade normativa, democracia e controle social: reflexões sobre alguns rumos do Direito Público neste século. In Fundamentos do Estado de Direito. ÁVILA, Humberto. (org.). São Paulo: Malheiros Editores, 2005, p. 95.

${ }^{4}$ LUÑO, Antonio Henrique Perez. Derechos humanos, estado de derecho y constitucion. Madrid/Espanha: Rigorma, 1999, p. 214.

'STRECK, Lenio Luiz; MORAIS, José Luis Bolzan de. Ciência Política e Teoria Geral do Estado. 3 ed. Porto Alegre: Livraria do Advogado, 2003, p. 91.
} 
Assim, no Estado de Direito liberal, a legitimidade da ação se converte em legalidade - que consiste na subsunção dos fatos a um sistema pré-determinado de regras, que garantiria a estabilidade das relações e o conhecimento antecipado do comportamento do Estado, convertendo-se a lei no epicentro de um sistema de poder e contra-poder, onde desaparece o sujeito ou instância com autonomia absoluta para impor sua vontade.

Especialmente no pós-guerra, o restabelecimento da democracia em muitos países contribuiu, de forma decisiva, para a difusão e a incorporação do Estado Social de Direito nas Constituições, como no Brasil, em que, ao Estado, foram atribuídas tarefas de natureza social a demandar intervenções estatais positivas. O alargamento dessas tarefas coloca a questão da sua vinculação à legalidade. Sinaliza-se, assim, para a orientação das atividades do Estado como programas-fim, de maneira que resta, nesses casos, à administração, executá-las da forma que mais lhe pareça adequada, o que não afasta a possibilidade de controle externo.

O Estado, portanto, vai gradativamente abandonando sua feição estritamente liberal-absenteísta e passa a agir positivamente para a garantia de uma liberdade que não se satisfaz apenas negativamente. Esse agir positivo gera a colocação de novos problemas para a forma de estruturação de incidência das normas jurídicas. A legalidade, agora incapaz de atender a complexidade da vida social, impõe a necessidade de refletir-se sobre as medidas de que dispõe o Estado para tornar efetivos os direitos fundamentais em sua integralidade, assim como os fins, objetivos e valores postos na Constituição - a fonte legitimadora de suas ações.

Tal perspectiva também abre espaço para uma nova forma de interpretar a Constituição. Atualmente, diversamente do que ocorria nos primeiros passos do constitucionalismo moderno, não se destina mais a proporcionar seja a supremacia seja o retraimento do Estado em face dos direitos da sociedade civil, tal como ocorreu em sua inspiração absolutista, em um primeiro momento, e liberal, posteriormente. De forma abrangente, o que se espera hoje de uma Constituição são linhas gerais para guiar a atividade estatal e social, de forma a promover o bem-estar individual e coletivo dos 
integrantes da comunidade que soberanamente a estabelecem ${ }^{6}$.

O Estado projetado pelo já referido movimento de constitucionalização havido nas décadas que seguiram ao PósGuerra, hoje, passadas algumas décadas de experiência, tem que conviver com significativas transformações no campo social, político e econômico, o que demanda uma (re)avaliação das instituições que compõem os seus setores.

A partir dessas transformações - que implicam uma série de consequências para o Estado - o Estado e o Direito experimentam, cada vez mais, uma redução a instrumentos para a adaptação ao câmbio contínuo e à complexidade social. Passaram - o Estado e o Direito - à condição de meios de direção social e não somente, nem preferencialmente, de organização e controle de situações, relações sociais e de tráfico de bens, mas pela ação de todos os tipos de assuntos para a efetividade dos processos sociais.

Nesse viés, de acordo com Gustavo Zagrebelski, o, reconhecimento do pluralismo nas Constituições Democráticas é simplesmente uma proposta de soluções e coexistências possíveis, ou seja, é um "compromiso de las posibilidades" e não um projeto rigidamente ordenado. Somente assim é que se pode pensar em Constituições "abertas", que contemplem tanto a espontaneidade da vida social como a competição para assumir a direção política condições necessárias para uma sociedade pluralista e democrática?

Sob pena de esses desenvolvimentos constituírem-se exercício de mera retórica, há que se reconhecer que, no contexto atual reconhecidamente atingido pelos efeitos do fenômeno da globalização e da reinante política e economia do "Estado mínimo", impulsionada pelo "consenso neoliberal" -, difunde-se uma grave crise do Estado democrático de Direito, que se converte também em uma crise de efetividade dos direitos fundamentais, como salienta Ingo Sarlet ${ }^{8}$. Não há como pensar em tutela de direitos fundamentais hoje, sem pensar na (re)afirmação dos referenciais que marcam o

${ }^{6}$ GUERRA FILHO, Willis Santiago. Derechos fundamentales, proceso y principio de proporcionalidad. In Revista de Processo. Ano 24, n. 95, jul-set 1999, p. 67.

7ZZAGREBLSKI, Gustavo. El derecho dúctil. Torino: Giulio Einaudi Editore: 1992, p. 15.

"SARLET, Ingo Wolfgang. Constituição e Proporcionalidade: o direito penal e os direitos fundamentais entre proibição de excesso e de insuficiência. In: Boletim da Faculdade de Direito de Coimbra, n. 81 (2005), p. 325-386. 
desenvolvimento do Estado Democrático de Direito.

É a partir da perspectiva abordada que emerge a noção de políticas públicas, como meio capaz de estimular a realização das atribuições constitucionais, especialmente dos direitos fundamentais, a partir da formulação de programas de ações que se diferenciam da estrutura normativa tradicional (se, então). Enquanto garantidoras de direitos inscritos no quadro normativo vigente no Brasil, torna-se evidente que as políticas públicas estão efetivamente inscritas no Direito. O tema das políticas públicas é, portanto, o que se passa a abordar no tópico seguinte.

\section{CONSIDERAÇÕES SOBRE O CONCEITO DE POLÍTICAS PÚBLICAS E O SEU PAPEL NO CONTEXTO DO ESTADO DEMOCRÁTICO DE DIREITO CONTEMPORÂNEO}

O conceito de políticas públicas não recebe contornos definitivos e rígidos na doutrina brasileira. Em linhas gerais, ele pode ser designado para o conjunto das atividades estatais tendentes a promover o complexo de deveres de intervenção atribuídos ao Estado pela Constituição Federal de 1988. Tal definição, contudo, não é totalmente satisfatória, principalmente quando entram em pauta debates como a possibilidade de controle judicial das políticas públicas.

No contexto geral das Constituições do Pós-Guerra - e, vale frisar, a inclusão dos chamados direitos sociais em grande parte dos textos constitucionais que decorreram desse período -, as políticas públicas assumem o papel de realizar essa prestação do Estado. Formalmente, pode-se aduzir que elas são leis que compõem um processo de planificação da intervenção do Estado na vida social e política de um país. Assim, a estrutura de "política pública" embora não se possa desconsiderar a sua presença anteriormente a esse período de surgimento das Constituições do pós-guerra - é manejado para tornar efetivas as opções realizadas pelos poderes legislativo e executivo, no contexto das atribuições constitucionais. Assim, aponta-se no sentido de que os "fins a serem obtidos, parâmetros das ações, programas de ações - indicadores das políticas, instrumentos e caminhos para a realização de ações -, tudo 
isto é normatizado, inicialmente, pela Constituição "."

Nesse sentido, mostra Maria Paula Dallari Bucci que "a necessidade de compreensão das políticas públicas como categoria jurídica se apresenta à medida que se buscam formas de concretização dos direitos humanos, em particular os direitos sociais ${ }^{10}$." A partir dessas considerações, decorre a perspectiva que permeará o conceito de políticas públicas.

As considerações pontuadas por Patrícia Massa-Arzabe apontam no sentido de que a noção de políticas públicas vai além da usual forma de intervenção do poder público na vida social por meio de regras jurídicas. As políticas públicas apresentam um perfil de intervenção diferenciado, que compõe "o conjunto de ações e programas continuados no tempo, que afetam simultaneamente várias dimensões das condições básicas de vida da população, organizados numa determinada área de implantação "."

Esclarecidas, em linhas gerais, as finalidades e o contexto em que se colocam as políticas públicas, cabe buscar sua definição. Nesse sentido, uma primeira conceituação é extraída da investigação de Maria Paula Dallari Bucci, que constrói a seguinte definição de políticas públicas:

(...) programa de ação governamental que resulta de um processo ou conjunto de processos juridicamente regulados - processo eleitoral, processo de planejamento, processo de governo, processo orçamentário, processo legislativo, processo administrativo, processo judicial - visando concretizar os meios à disposição do Estado e as atividades privadas, para a realização de objetivos socialmente relevantes e politicamente determinados. (BUCCI, 2006, p. 39)

Fernando Aith, por sua vez, considera política pública como

\footnotetext{
'DERANI, Cristiane. Politica pública e norma politica. In BUCCI, Maria Paula Dallari. (org.) Políticas Públicas: reflexões sobre o conceito jurídico. São Paulo: Saraiva, 2006, p. 136.

${ }^{10} \mathrm{BUCCI}$, Maria Paula Dallari. O conceito de politicas públicas em direito. In BUCCI, Maria Paula Dallari (org.). Políticas Públicas: reflexões sobre o conceito jurídico. São Paulo: Saraiva, 2006,p. 03.

"MASSA-ARZABE, Patrícia Helena. Dimensão juridica das políticas públicas. In BUCCI, Maria Paula Dallari. (org.) Políticas Públicas: reflexões sobre o conceito jurídico. São Paulo: Saraiva, 2006,p. 62.
} 
"atividade estatal de elaboração, planejamento, execução e financiamento de ações voltadas à consolidação do Estado Democrático de Direito e à promoção e proteção dos direitos humanos ${ }^{12}$ ".

Avançando na explanação do tema, cita-se Rogério Gesta Leal, que define política pública como uma "ação estratégica (de instituições ou pessoas de direito público) que visa a atingir fins previamente determinados por finalidades, objetivos e princípios de natureza pública, ${ }^{13}$ " o que acontece por meio de uma racionalidade programática, que se caracteriza por medidas organizacionais e de planejamento.

Em que pese não se descuidar das inúmeras implicações que a matéria apresenta, não cabe aqui discorrer exaustivamente acerca das variadas conceituações explicitadas pelos doutrinadores, o que

\footnotetext{
${ }^{12}$ AITH, Fernando. Politicas Públicas de Estado e de governo: instrumentos de consolidação do Estado Democrático de Direito e de proteção dos direitos humanos. In BUCCI, Maria Paula Dallari (org.). Políticas Públicas: reflexões sobre o conceito jurídico. São Paulo: Saraiva, 2006, p. 232.

${ }^{13}$ LEAL, Rogério Gesta. O controle jurisdicional de politicas públicas no Brasil: possibilidades materiais. In SARLET, Ingo Wolfgang. (org.) Jurisdição e Direitos Fundamentais. Porto Alegre: Livraria do Advogado, 2005, p. 157-178. O autor aponta que os direitos e garantias fundamentais constituem-se em parâmetros vinculativos de todos os atos praticados por agentes públicos e pela comunidade, no sentido de estarem efetivamente comprometidos com a realização destas garantias. A partir de tal premissa, o autor afirma: "Isto me leva a crer na existência daquilo que vou chamar de politicas públicas constitucionais vinculantes, aqui entendidas como aquelas ações que o Texto Político atribui aos Poderes Estatais como efetivadoras de direitos e garantias fundamentais, e todas as decorrentes delas, haja vista os níveis compartidos de responsabilidades entre as entidades federativas brasileiras e a cidadania envolvendo a matéria. Considerando ainda crer, no particular, não existirem normas constitucionais despossuídas de concreção no sistema jurídico pátrio, resulta claro que a responsabilidade de que estamos falando aqui é, diferenciadamente, pró-ativa dos poderes instituídos, merecendo imediata implementação." Dentre os exemplos citados pelo autor, pode-se apontar o disposto no artigo $5^{\circ}$, inciso XXXIV, que exigiria uma politica pública que viabilizasse a obtenção de certidões em repartições públicas, para defesa de direitos e esclarecimento de situações de interesse pessoal e o disposto no artigo $5^{\circ}$, incisos LXVIII, XLIX e L, que exigiria políticas públicas prisionais, a fim de garantir que a restrição da liberdade se dê de maneira a dar guarida às prerrogativas de que a pena seja cumprida em estabelecimentos distintos, de acordo com a natureza do delito, a idade e o sexo do apenado; que seja assegurado aos presos o respeito à integridade física e moral, e que às presidiárias sejam asseguradas condições para que possam permanecer com seus filhos durante o período de amamentação. Nesse sentido, afirma o autor que "para cada plexo de garantias outorgadas à responsabilidade estatal, necessitam advir políticas públicas concretizadoras que se operam em diversos níveis de efetivação (...). Tais ações é que denomino de políticas públicas constitucionais vinculantes, independentes da vontade ou discricionariedade estatal para que venham a acontecer, eis que condizentes a direitos indisponíveis e da mais alta importância e emergência comunitárias, perquirindo imediata materialização, sob pena de comprometer a dignidade humana e o mínimo existencial dos seus carecedores".
} 
se dá em função da própria novidade que o tema representa para c campo jurídico. Em linhas gerais, opta-se pela adoção de uma noçãc ampliada do conceito de políticas públicas, tal como propõem as designações acima apresentadas, tendo em conta sobretudo que a noção de política pública ultrapassa a prestação de serviços públicos pelo Estado e o desenvolvimento de atividades meramente executivas, envolvendo também uma perspectiva normativa, reguladora e de fomento que se estende sobre as mais diversas áreas.

Para a compreensão do que pode ser considerado como uma política pública faz-se a tentativa de estabelecer quais elementos compõe a sua estrutura. Trata-se, portanto, do que sempre pode ser identificado em uma política pública. Pode-se enumerar, em linhas gerais, alguns elementos que compõem essas leis que orientam as políticas públicas e que são, segundo Maria Paula Dallari Bucci: fins, objetivos, princípios, diretrizes, instrumentos e sistema ${ }^{14}$. Vêse, assim, que uma política pública compõe um conjunto de medidas que se articulam, tendo como objetivo impulsionar o aparelho do governo para realizar algum objetivo de ordem pública ou, numa perspectiva jurídica, concretizar um direito.

Para desempenhar suas funções, as políticas poderão apresentar distintos suportes legais, que podem ser expressos "em disposições

\footnotetext{
${ }^{14} \mathrm{BUCCI}$, Maria Paula Dallari. O conceito de politicas públicas em direito. In BUCCI, Maria Paula Dallari (org.). Políticas Públicas: reflexões sobre o conceito jurídico. São Paulo: Saraiva, 2006, p. 12. Nesse sentido, cabe um alerta importante no que diz respeito à "política" no plano constitucional: "No que diz respeito à saúde, o art. 196 da Constituição dispõe: A saúde é direito de todos e dever do Estado, garantido mediante políticas sociais e econômicas que visem à redução do risco de doença $\mathrm{e}$ de outros agravos $\mathrm{e}$ ao acesso universal e igualitário às ações e serviços para sua promoção, proteção e recuperação. Mas mais importante que essa definição é a própria estruturação das prestações estatais em matéria de saúde, que a Constituição Federal ordenou, de forma inédita, no Sistema Único de Saúde. Resultante de um aprimoramento de modelos anteriores à Constituição de 1988, a partir da evolução das primeiras propostas téenicas, mas, mais importante, agregando a mobilização política e social do movimento pela democratização da saúde, o SUS, é inscrito nos arts. 198 a 200 da Constituição, com vistas a alcançar o nível máximo de garantia proporcionado pelo sistema jurídico. Seria de se pensar se isso não desnaturaria o seu caráter de politica pública, que, como vimos, tem como nota distintiva atingir objetivos sociais em tempo e quantidade previamente determinados. O SUS não é um programa que visa resultados, mas uma nova conformação, de tipo estrutural, para o sistema de saúde, cujo objetivo é a coordenação da atuação governamental nos diversos níveis federativos no Brasil ("rede regionalizada e hierarquizada", cf. art. 198 da CF), para a realização de três diretrizes: descentralização, atendimento integral prioritariamente preventivo e participação da comunidade."(p.17-18)
} 
constitucionais, ou em leis, ou ainda em normas infralegais, como decretos e portarias e até mesmo em instrumentos jurídicos de outra natureza, como contratos de concessão de serviço público, por exemplo ${ }^{15 "}$.

De acordo com as lições de Maria Paula Dallari Bucci, as políticas públicas podem ser entendidas como atividade, como o faz Fábio Konder Comparato, ${ }^{16}$ ou como categoria normativa. Sob o primeiro aspecto, pondera que se estaria diante de uma categoria jurídica nova, a partir da noção de atividade. Disso deriva a possibilidade de julgar determinada política inconstitucional sem que os atos ou normas que a estruturam sejam em si inconstitucionais. Já sob o segundo enfoque - as políticas públicas como categoria normativa, - seguindo o raciocínio do jusfilósofo americano Ronald Dworkin, enfatiza que as políticas, diferentemente das leis, não são gerais e abstratas, mas, ao contrário, são forjadas para a realização de objetivos determinados. Nesse sentido,

(...) poder-se-ia dizer que as politicas públicas atuam de forma complementar, preenchendo os espaços normativos e concretizando os principios e regras, com vista a objetivos determinados. Caberia, então, encontrar lugar (ou melhor, os seus contornos) para uma categoria jurídico-formal, situada provavelmente abaixo das normas constitucionais e acima ou ao lado das infraconstitucionais. Por esse raciocinio, as políticas públicas corresponderiam, no plano jurídico, a diretrizes, normas de um tipo especial, na medida em que romperiam as amarras dos atributos de generalidade e abstração-que extremam as normas dos atos jurídicos, esses sempre concretos -, para dispor sobre matérias contingentes. (BUCCI, 2006, P. 26)

\footnotetext{
${ }^{15}$ BUCCI, Maria Paula Dallari. O conceito de politicas públicas em direito. In BUCCI, Maria Paula Dallari (org.). Políticas Públicas: reflexões sobre o conceito jurídico. São Paulo: Saraiva, 2006, p. 11.

${ }^{16} \mathrm{~A}$ concepção de políticas públicas como atividade pode ser encontrada em COMPARATO, Fabio Konder. Ensaio sobre o juizo de constitucionalidade de políticas públicas. In MELLO, Celso Antonio Bandeira de (org.) Estudos em homenagem a Geraldo Ataliba 2: direito administrativo e constitucional. São Paulo: Malheiros Editores, 1997, p. 352 e ss. Igualmente, no artigo O Ministério Público na defesa dos direitos econômicos, sociais e culturais. In GRAU, Eros Roberto; CUNHA, Sérgio Sérvulo da. Estudos de Direito Constitucional em homenagem a José Afonso da Silva. São Paulo: Malheiros Editores, 2003, p. 244-260.
} 
Constata-se que a atividade de governar muda de configuração, pois o government by policies coloca-se como um meio alternativo ao government by law, passando a exigir o exercício combinado de várias tarefas em que o governar não se restringe à administração da conjuntura, mas, sobretudo, ao planejamento do futuro, por meio do estabelecimento de políticas de médio e longo prazos ${ }^{17}$.

Desde o enfraquecimento do poder reverencial à lei, em que a legitimidade do Estado deixa de fundar-se na expressão legislativa da soberania popular, e passa também a guiar-se pela realização de metas coletivas, "o critério classificatório das funções e, portanto, dos Poderes estatais só pode ser o das políticas públicas ou programas de ação governamental ${ }^{18}$." Em que pese não se poder visualizar uma necessidade perene e inflexível nas formas de atuação do Estado, ressalta-se a importância de tal reconhecimento a partir das novas configurações que regem as relações entre Estado e sociedade $^{19}$. A falta de uma conseqüente reorganização dos Poderes que permita absorver tais transformações e que dê preeminência à função planejadora é que, no entendimento de Comparato, acaba por incumbir o Governo (segundo o autor, impropriamente chamado de Poder Executivo) hegemonicamente, do papel de realizar tal planejamento.

\footnotetext{
${ }^{17} \mathrm{~A}$ idéia é apresentada por Fábio Konder Comparato, que salienta: "a norma geral regula as ações humanas, mas não the dá um sentido concreto; delimita o campo da liberdade, pela definição de fronteiras entre o permitido e o proibido, mas não se substitui à vontade individual na escolha de objetivos de vida. O sistema normativo organiza, em suma, a convivência humana de um modo por assim dizer negativo: o que se põe em foco, pelo papel saliente atribuído à sanção, é o que não se deve fazer." Ensaio sobre o juizo de constitucionalidade de politicas públicas. In MELLO, Celso Antonio Bandeira de (org.) Estudos em homenagem a Geraldo Ataliba 2: direito administrativo e constitucional. São Paulo: Malheiros Editores, 1997, p. 345.

${ }^{18}$ COMPARATO, Fabio Konder. Ensaio sobre ojuizo de constitucionalidade de politicas públicas. In MELLO, Celso Antonio Bandeira de (org.) Estudos em homenagem a Geraldo Ataliba 2: direito administrativo e constitucional. São Paulo: Malheiros Editores, 1997, p. 345.

${ }^{19}$ Nesse ponto, remete-se às ponderações de Ingo Sarlet acerca da conclusão a que chega o autor sobre a relação entre as ações do Estado, os direitos fundamentais e as políticas públicas: $\boldsymbol{A}$
} 
Sinaliza-se, assim, para uma substituição da tradicional conformação normativa se-então por meio-fim. Observa-se que a idéia de promoção de direitos e de fomento dos fins e objetivos propostos pela Constituição da República passa por uma forma de perceber a conformação das atividades estatais. Nesse viés, colhe-se a lição de Patrícia Massa-Arzabe, no sentido de que a política pública funciona de uma forma diversa da norma estruturada sobre a coerção, já que o caráter repressivo da norma tradicional não é capaz de atender à complexidade das situações disseminadas e culturalmente toleradas na sociedade. Ao contrário, a estrutura da política pública permite encaminhamentos mais razoáveis dos problemas, inclusive, porque, pela via de implementação das políticas, criam-se espaços de comunicação entre Estado e sociedade $^{20}$.

Por meio desse mecanismo estatal (e não-estatal), vislumbra-se uma possibilidade de aproximação do Estado com a comunidade para resolução de seus problemas, constituindo-se, portanto, uma via democrática de discussão.

Indo além, a própria noção de política pública só tem razão de ser (e só pode se desenvolver) em meio a condições que são próprias de um Estado que não corresponde ao Estado absenteista, e sim a um Estado que possua condições de operacionalizar, por meio de seu aparato administrativo, uma política pública.

Do que foi até aqui exposto, formula-se a percepção de que há uma imbricação necessária entre a nova perspectiva atribuída às políticas públicas e o direito, que, por sua vez, está circunscrita em uma nova percepção das relações entre o direito e a política e passa pelo reconhecimento de que as políticas públicas contemporâneas estão efetivamente inscritas no direito ${ }^{21}$.

A atuação estatal envolve, como demonstrado, a aplicação da Constituição e o cumprimento de suas normas, cabendo ao legislador a tarefa de disciplinar os mais variados temas de acordo

\footnotetext{
${ }^{20}$ MASSA-ARZABE, Patrícia Helena. Dimensão juridica das politicas públicas. In BUCCI, Maria Paula Dallari. (org.) Políticas Públicas: reflexões sobre o conceito juridico. São Paulo: Saraiva, 2006, p. 57.

${ }^{21}$ MASSA-ARZABE, Patrícia Helena. Dimensão juridica das politicas públicas. In BUCCI, Maria Paula Dallari. (org.) Políticas Públicas: reflexões sobre o conceito jurídico. São Paulo: Saraiva, 2006,p. 52
} 
com as disposições constitucionais e ao juiz aplicar a Constituição, direta ou indiretamente. No entanto, levando em consideração que a prestação jurisdicional ficará, de regra, adstrita às partes e que a legislação dependerá de atos da execução para se materializar, cabe à Administração Pública "efetivar os comandos gerais contidos na ordem jurídica e, em particular, garantir e promover os direitos fundamentais em caráter geral ${ }^{22}$." Como decorrência será necessário, portanto, implementar o que foi descrito como política pública.

As políticas públicas, como se constata, estão situadas em uma zona limítrofe entre o Direito e a Política, cujas interseções e conseqüentes repercussões têm gerado grandes debates para a constitucionalização do direito (contemporaneamente). Considerando que a Constituição representa, para o constitucionalismo contemporâneo, uma ascendência sobre o sistema político, parece natural que a política encontre seus limites nas normas emanadas da Constituição. A Constituição retira alguns campos da discricionariedade política, de maneira que o conteúdo político absorvido pela Constituição torna-se, também, afeto ao campo do Direito, como pondera Clémerson Mérlin Cléve ${ }^{23}$.

A idéia expressa pelo autor é importante porque dá um sentido para a forma como se desenvolvem, a partir do Estado Democrático de Direito (de um Direito que se realiza a partir da Constituição), as ações do Estado, tanto conformando limites materiais e formais para a atuação do Estado, como indicando os caminhos em que se faz necessária a sua atuação. Nesse contexto, afirma Clémerson Cléve, quando a Constituição define alguns aspectos, retira uma série de outros do debate político. Assim, apresenta uma dimensão política e outra despolitizadora, de maneira que isto que está definido politicamente é Direito, ficando fora do debate político, seja porque

\footnotetext{
${ }^{22}$ BARCEllos, Ana Paula de. Constitucionalização das Politicas Públicas em Matéria De Direitos Fundamentais: o Controle Político-Social e o Controle Juridico no Espaço Democrático. In SOUZA NETO, Cláudio Pereira de; SARMENTO, Daniel. (orgs.) A constitucionalização do Direito: Fundamentos Teóricos e Aplicações Específicas. Rio de Janeiro: Lúmen Juris, 2007, p. 604.

${ }^{20} \mathrm{CLÉVE}$, Clémerson Mérlin. $O$ controle de constitucionalidade e a efetividade dos direitos fundamentais. In SAMPAIO, José Adércio Leite (coord.) Jurisdição constitucional e direitos fundamentais. Belo Horizonte: Del Rey, 2003, p. 385-393.
} 
são princípios fundamentais, ou são objetivos fundamentais, ou são cláusulas pétreas ou porque são direitos fundamentais. $\mathrm{O}$ papel da política, nessa circunstância, é decidir o "como" porque "o quê", já está definido a partir da Constituição ${ }^{24}$.

Partindo de tais considerações, percebe-se que a noção de políticas públicas inscreve-se em um quadro de alteração dos tradicionais referenciais do Direito, constituindo-se em um importante instrumento para as ações do Estado destinadas à proteção e à promoção de todos os direitos fundamentais.

Cabe ressaltar que as considerações expostas não querem significar a atribuição de poderes irrestritos ao judiciário bem como qualquer negligência ao princípio da separação dos poderes - que se constitui, igualmente, princípio basilar do Estado Democrático de Direito-, mas pretendem demonstrar que, enquanto parte do quadro normativo, as normas de Direito Constitucional têm eficácia e devem ser aplicadas, o que, necessariamente, implicará refletir acerca dos pressupostos de uma tradição jurídica construída a partir do positivismo formalista.

\section{CONSIDERAÇÕES FINAIS}

Como se pode depreender a partir da análise histórica e das perspectivas que se vislumbram para o Estado Contemporâneo, existe uma mudança profunda na forma como estão balizadas as relações entre Constituição/Política e Estado/Sociedade, que repercutem de forma incisiva sobre a legitimação da atuação do Estado.

Desde o surgimento do Estado e até dos direitos fundamentais, uma série de novos problemas foram se colocando, de maneira que, atualmente, se lida com um campo muito diverso daquele em que tais instituições foram concebidas. Os direitos constitucionalmente assegurados, longe de se concretizarem apenas a partir de um dever de abstenção do Estado, têm demandado sua atuação positiva, cujas complexidades e peculiaridades tornam necessário pensar novas

\footnotetext{
${ }^{24}$ CLÉVE, Clémerson Mérlin. $O$ controle de constitucionalidade e a efetividade dos direitos fundamentais. In SAMPAIO, José Adércio Leite (coord.) Jurisdição constitucional e direitos fundamentais. Belo Horizonte: Del Rey, 2003, p. 385-393
} 
formas de intervenção normativa pelo Estado. Nesse contexto é o que se coloca a noção de políticas públicas.

As políticas públicas se diferenciam da norma estruturada sobre a coerção em função de promoverem ações estatais a partir do preceito medida-fim, o que é capaz de atender de forma mais eficaz a complexidade das questões sociais.

A conclusão de que as políticas públicas efetivamente inscrevem-se no plano do Direito tem conseqüências significativas para a análise que se projeta para a garantia dos direitos fundamentais, pois ela permitirá que as questões socialmente relevantes sejam objeto de consideração e análise por parte dos operadores do Direito, os quais, continuamente, lidam com questões postas numa interseção entre o jurídico e o político.

\section{REFERÊNCIAS BIBLIOGRÁFICAS}

ÁVILA, Humberto (org.) Fundamentos do Estado de Direito. São Paulo: Malheiros Editores, 2005.

BUCCI, Maria Paula Dallari (org.). Políticas Públicas: reflexões sobre o conceito jurídico. São Paulo: Saraiva, 2006.

GRAU, Eros Roberto; CUNHA, Sérgio Sérvulo da. Estudos de Direito Constitucional em homenagem a José Afonso da Silva. São Paulo: Malheiros Editores, 2003.

GUERRA FILHO, Willis Santiago. Derechos fundamentales, proceso y principio de proporcionalidad. In: Revista de Processo. Ano 24, n. 95, jul-set 1999, p. 67.

LUÑO, Antonio Henrique Perez. Derechos humanos, estado de derecho y constitucion. Madrid/Espanha: Rigorma, 1999.

MELLO, Celso Antonio Bandeira de (org.) Estudos em homenagem a Geraldo Ataliba 2: direito administrativo e constitucional. São Paulo: Malheiros Editores, 1997.

SAMPAIO, José Adércio Leite (coord.) Jurisdição constitucional 
e direitos fundamentais. Belo Horizonte: Del Rey, 2003.

SARLET, Ingo Wolfgang. Constituição e Proporcionalidade: o direito penal e os direitos fundamentais entre proibição de excesso e de insuficiência. In: Boletim da Faculdade de Direito de Coimbra, n. 81 (2005).

SARLET, Ingo Wolfgang. (org.) Jurisdição e Direitos Fundamentais. Porto Alegre: Livraria do Advogado, 2005.

SARLET, Ingo Wolfgang. A eficácia dos direitos fundamentais. 9 ed. Porto Alegre: Livraria do Advogado, 2007.

SOUZANETO, Cláudio Pereira de; SARMENTO, Daniel. (orgs.) A constitucionalização do Direito: fundamentos teóricos explicações específicas. Rio de Janeiro: Lúmen Juris, 2007.

STRECK, Lenio Luiz; MORAIS, José Luis Bolzan de. Ciência Política e Teoria Geral do Estado. 3 ed. Porto Alegre: Livraria do Advogado, 2003.

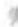

ZAGREBELSKI, Gustavo. El derecho dúctil. Torino: Giulio Einaudi Editore: 1992. 